\title{
Öznel Sıkıntıları Açma Ölçeği: Geçerlik ve Güvenirlik Çalışmaları ${ }^{1}$
}

\section{Onur GÜRSOY² Cem Ali GiziR ${ }^{3}$}

\section{Öz}

$\mathrm{Bu}$ çalışmanın amacı, Kahn ve Hessling tarafından geliştirilen Öznel Sıkıntıları Açma Ölçeğini (ÖSAÖ) Türkçe’ye uyarlayarak geçerlik ve güvenirliğini incelemektir. Araştırma verileri, Mersin Üniversitesinin çeşitli fakültelerinde öğrenim gören 311 (195 kadın, 116 erkek) üniversite öğrencisinden elde edilmiştir. Ölçeğin yapı geçerliği, doğrulayıcı faktör analizi yöntemi ile sınanmıştır. Faktör analizi sonuçları ölçeğin, "kendini açma" ve "kendini gizleme" olarak betimlenen iki uçlu (bipolar) ve tek faktörlü bir yapıya sahip olduğunu göstermiştir. Güvenirlik çalışmaları kapsamında ÖSAÖ için hesaplanan Cronbach alfa iç tutarlık katsayısı .91 olarak belirlenmiştir. Ölçeğin üç hafta ara ile uygulanması sonucu elde edilen test-tekrar test güvenirliği ise $.85^{\prime}$ tir. Sonuç olarak, yapılan geçerlik ve güvenirlik çalışmaları doğrultusunda tek faktörlü bu ölçeğin üniversite öğrencilerinde kullanılabilecek geçerli ve güvenilir bir ölçme aracı olduğu belirlenmiştir.

Anahtar Kelimeler: Öznel sıkıntılar, kendini açma, kendini gizleme, üniversite öğrencileri, geçerlik, güvenirlik.

\footnotetext{
${ }^{1}$ Bu çalışma, Onur Gürsoy tarafından Mersin Üniversitesi, Eğitim Bilimleri Enstitüsü’nde Doç. Dr. Cem Ali Gizir danışmanlığında yapılan yüksek lisans tez çalışmasının bir bölümüdür.

${ }^{2}$ Uzm. Onur GÜRSOY, Mersin Üniversitesi, PDR Merkezi, Mersin. e-posta: onur_gursoy2@ hotmail.com

${ }^{3}$ Doç. Dr. Cem Ali GİZIR, Mersin Üniversitesi, Eğitim Fakültesi, Mersin. e-posta: cagizir@mersin.edu.tr
} 


\title{
Distress Disclosure Index: Validity and Reliability Studies
}

\begin{abstract}
The purpose of the present study is to adapt the Distress Disclosure Index (DDI) which was originally developed by Kahn and Hessling to Turkish and examine the validity and reliability of the scale. The data was collected from 311 (195 female, 116 male) undergraduate students enrolled at Mersin University. Confirmatory factor analysis was used to determine the construct validity of the scale. Results of the study revealed a unidimensional construct based on a bipolar spectrum of "self-disclosure" and "self-concealment". The results also indicated that internal consistency for the 12-item DDI as estimated by Cronbach's alpha was .91 and test-retest (three weeks interval) correlation coefficient was .85. As a result, all the findings suggested that the DDI can be used as a valid and reliable instrument for measuring the tendencies of university students to conceal or disclose their personal distress.
\end{abstract}

Key Words: Distress disclosure, self disclosure, self concealment, university students, validity, reliability. 


\section{Giriş}

Üniversite yaşamı, ergenlikten genç yetişkinliğe adım atan 18-25 yaş arasındaki gençlerin çeşitli yeni yaşantıları deneyimledikleri önemli bir gelişim dönemi olarak nitelendirilmektedir. $\mathrm{Bu}$ dönemde, üniversitenin yeni akademik ve sosyal ortamına uyum sağlama, akademik beklentileri karşılama, sosyal özgürlükler içinde bağımsız olma, arkadaş ve karşı cinsle olan ilişkilerini sorgulama ve çeşitli kariyer olanaklarını araştırma gibi birçok konu, üniversite öğrencilerinin temel gündemini oluşturmaktadır (Gizir, 2005). Bir başka deyişle, bu dönemde üniversite öğrencileri, akademik, mesleki, kişisel ve sosyal açıdan birçok sorunla başa çıkmaya çalışmaktadırlar (Sevinç ve Gizir, 2014).

Diğer yandan, birçok farklı alanda çeşitli sorunlarla başa çıkmak zorunda olan üniversite öğrencilerinin gereksinim duymalarına rağmen oldukça sınırlı oranda profesyonel psikolojik yardım alma davranışı sergiledikleri (Raunic ve Xenos, 2008; Rosenthal ve Wilson, 2008; Stallman ve Shocket, 2009) ve bu öğrencilerin psikolojik yardım almaya sadece yaşadıkları sorunların şiddeti arttığında yöneldikleri (Turner ve Quin, 1999) belirtilmektedir. $\mathrm{Bu}$ bağlamda, günümüzde gerçekleştirilen birçok araştırma bulgusu, bireylerin psikolojik yardım alma davranışları ile yakından ilişkili ve en önemli faktörlerden birinin de kendini açma düzeyi olduğunu ortaya koymaktadır (Greenidge, 2007; Greenidge ve Daire, 2010; Kakhnovets, 2011; Komiya ve Eels, 2001; Komiya, Good ve Sherrod, 2000; Koydemir, Erel, Yumurtacı ve Şahin, 2010; Özbay, Terzi, Erkan ve Cihangir-Çankaya, 2011; Vogel ve Wester, 2003; Vogel, Wester ve Larson, 2007; Vogel, Wester, Wei ve Boysen, 2005).

Kendini açma, bireyin kişisel sorunları hakkında diğerleri ile konuşurken gösterdiği rahatlık derecesi olarak tanımlanmaktadır (Vogel ve Wester, 2003). Cozby'e (1973) göre kendini açma davranışı, iki karşıt faktörün ürünü olarak değerlendirilmektedir. $\mathrm{Bu}$ faktörlerden ilki kendini açmayı artırmayı, diğeri ise azaltmayı temsil etmektedir. Aslında kendini açma, ilişki kurma ihtiyacı, iletişime geçme, diğer insanlara karşı dürüst ve açık olma gibi karşılıklı grup davranışları ile yakından ilişkili bir kavramdır. Bu noktada Cozby, toplumsal olarak kendini açma davranışının çoğunlukla olumlu bir değer olarak tanımlanmakta olduğunu ve toplum tarafından teşvik edildiğini belirtmektedir. Diğer yandan Cozby, ağız sıkılığı ya da gizlilik ihtiyacı olarak tanımlanan bazı faktörlerin de kendini açma davranışını azalttığını ifade etmektedir.

Jourard (1979) ise genel olarak bireyin kendine ait özel/gizli bilgileri diğerleri ile paylaşması olarak tanımladığı kendini açma davranışının, aile içinde geliştiğini ve bireyin 
ergenlik ve yetişkinlik dönemlerindeki ilişkilerini önemli ölçüde etkilediğini belirtmiştir. Aynı zamanda Jourard, kendini açma davranışının psikolojik sağlığın devam ettirilebilmesi için gerekli olduğuna vurgu yapmaktadır. Günümüzde gerçekleştirilen birçok araştırma bulgusu da bu varsayımı destekler nitelikte olup, yaşanılan sıkıntılar temelinde kendini açma düzeyi ile bireylerin psikolojik yardım almaya yönelik olumlu tutumları arasında pozitif yönde ve istatistiksel açıdan anlamlı bir ilişki olduğunu göstermektedir (Greenidge ve Daire, 2010; Kakhnovets, 2011; Komiya ve Eels, 2001; Komiya, Good ve Sherrod, 2000; Koydemir, Erel, Yumurtacı ve Şahin, 2010; Özbay, Terzi, Erkan ve Cihangir-Çankaya, 2011; Vogel, Wester ve Larson, 2007). İlgili alanyazında, kendini açma eğiliminin, artan sosyal destek, olumlu duygusal kişilik özelliği, genel psikolojik sağlamlık algısı ve etkili kişiler arası ilişkiler gibi birçok yararlı sonuçla ilişkili olduğu, kendini açma düzeyinin düşüklüğünün ise olumsuz duygusal kişilik özelliği ve şiddetli depresif semptomlarla ilişkili olduğu belirtilmektedir (Kahn ve Hessling, 2001). Yine, öz-farkındalık, sosyal destek ve kadınsı cinsiyet rollerinin bireyin kendini açma davranışlarıyla pozitif yönde, utanma duygusu ile ise negatif yönde bir ilişki içinde olduğu vurgulanmaktadır (Greenland, Maxwell, Prior ve Scourfield, 2009).

Diğer yandan, kendini açma ile birlikte kendini gizleme kavramına da alanyazında sıklıkla rastlanmaktadır (Cepeda-Benito ve Short, 1998; Cramer, 1999; Kahn ve Hessling, 2001; Kelly ve Achter, 1995). Bir bireyin bilinçli olarak duygularını, düşüncelerini, kişisel bilgilerini başkalarına anlatmaması olarak tanımlanan kendini gizleme (Larson ve Chastain, 1990), kendini açma kavramının tersi olarak nitelendirilmektedir. Bununla birlikte, kendini gizleme, hiçbir bireyle ve hiçbir koşulda bilgi paylaşmamak anlamına da gelmemektedir. Yapılan çalışmalar, kendini gizleme eğiliminde olan bireylerin yakın çevrelerinde bulunan bazı kişilere bir şekilde kendilerini açmalarına rağmen yaşadıkları örseleyici sorunlarını ya da olumsuz duygularını çoğunlukla saklama/gizleme eğiliminde olduklarını göstermektedir (Larson ve Chastain, 1990). Bununla birlikte Cramer (1999), kendini gizleme eğilimi sergileyen bireylerin daha az sosyal desteğe sahip olduklarını ve aynı zamanda daha çok psikolojik sıkıntı yaşadıklarını belirtmektedir. Diğer yandan, Capeda-Benito ve Short (1998) ise kendini gizleme eğilimi yüksek olan bireylerin daha sıklıkla yardım arama davranışı sergilediklerini ifade etmektedirler.

Kahn ve Hessling (2001) ise araştırmacıların bugüne dek kendini açma ve kendini gizleme kavramlarını birbirinden ayrıştırarak tanımladıklarını ve bireylerin kendini açma ve gizleme davranışlarını çalışmalarında iki farklı değişken olarak ele aldıklarını belirtmektedirler. Kahn ve Hessling’e (2001) göre kendini açma ve gizleme iki farklı 
kavramdan öte bir sürecin iki karşıt ucu (bipolar) olarak ele alınmalı ve ölçülmelidir. $\mathrm{Bu}$ bilgiler 1şığında, bu çalışmanın amacı, üniversite öğrencilerinin öznel sıkıntılarını açma düzeylerini belirlemeye yönelik çeşitli araştırmalarda kullanılabilecek olan Kahn ve Hessling (2001) tarafından geliştirilen Öznel Sıkıntıları Açma Ölçeğini (Distress Disclosure Index) Türkçe’ye uyarlayarak geçerlik ve güvenirliğini incelemektir.

Üniversite öğrencilerinin çeşitli alanlarda önemli psikolojik danışma gereksinimlerinin olduğu (Karataş ve Gizir, 2013) bilinmektedir. Bununla birlikte, son dönemlerde yürütülen çalışma bulguları, üniversite öğrencilerinin psikolojik yardım alma ya da arama tutumlarını olumsuz yönde etkileyen kişisel, kişilerarası ve sosyal birçok farklı faktör bulunduğu ortaya koymaktadır (Chang, 2007; Kahn ve Hessling, 2001; Kakhnovets, 2011; Kalkan ve Odac1, 2005; Kim, 2007; Komiya, Good ve Sharrod, 2000; Vogel, Wester ve Larson, 2007). Türkiye'de gerçekleştirilen çalışmalarda ise üniversite öğrencilerinin psikolojik yardım aramaya yönelik tutumları ile cinsiyet ve cinsiyet rolleri (Çebi, 2009; Özbay, Terzi, Erkan ve Cihangir-Çankaya, 2011; Kalkan ve Odacı, 2005; Türküm, 2005), algılanan sosyal destek (Çebi, 2009), stres kaynakları (Bahar, 2010), daha önce psikolojik yardım alma deneyimi (Koydemir-Özden ve Erel, 2010), kendini damgalama ve sosyal damgalama (Topkaya, 2014) değişkenleri arasındaki ilişkilerin incelendiği gözlemlenmektedir. Bu noktada, üniversite öğrencilerinin psikolojik yardım alma davranışları ile bipolar bir yapı oluşturduğu öngörülen kendini açma ya da gizleme eğilimleri arasındaki ilişkilerin belirlenmesi önem arz etmektedir. Dolayısıyla, Öznel Sıkıntıları Açma Ölçeği'nin kullanılması ile kendini açma ya da gizleme eğiliminin tek başına ya da yukarıda sözü edilen değişkenler ile birlikte aracı etkisi temelinde, üniversite öğrencilerinin yardım arama tutumları kapsamında yürütülecek çeşitli çalışmalarda kullanılabileceği ve ilgili alanyazına önemli katkılar sunabileceği öngörülmektedir.

\section{Yöntem}

\section{Çalışma Grubu}

Çalışma grubu, Mersin Üniversitesi'nin en büyük dört fakültesinde (Eğitim, Fen-Edebiyat, İktisadi ve İdari Bilimler, Mühendislik) öğrenim görmekte olan ve seçkisiz örnekleme yöntemiyle belirlenen 311 üniversite öğrencisinden oluşmaktadır. Çalışma grubunun 195 'i (\% 62.7) kadın ve 116’sı (\% 37.3) erkek öğrencilerden oluşmaktadır. Sınıf düzeyi açısından incelendiğinde, öğrencilerin 62'si (\% 19.9) birinci, 41'i (\% 13.2) ikinci, 101'i (\% 32.5) üçüncü ve 107'si (\% 34.4) dördüncü sınıfta öğrenim görmektedir. Katılımcıların yaşları ise 18 ile 26 arasında değişmekte olup, ortalaması $21.7^{\prime} \operatorname{dir}(S S=1.98)$. 


\section{Veri Toplama Araçları}

\section{Kişisel Bilgi Formu}

Çalışma grubunu betimlemek üzere öğrencilerin bölüm, sınıf ve cinsiyet gibi temel demografik özelliklerinin tanımlanması amacıyla araştırmacılar tarafından hazırlanan soru formudur.

\section{Öznel Sıkıntıları Açma Ölçeği (ÖSAÖ)}

Kahn ve Hessling (2001) tarafından geliştirilen Öznel Sıkıntıları Açma Ölçeği (Distress Disclosure Index), bireylerin öznel sıkıntılarını açma ya da gizleme eğilimlerini ölçme amacıyla kullanılmaktadır. Toplam 12 maddelik özgün ölçek, her biri 6 maddeden oluşan, "kendini açma" ve "kendini gizleme" olarak betimlenen iki uçlu (bipolar) ve tek faktörlü bir yapıya sahiptir. Farklı örneklem gruplarıyla yapılan çalışmalar sonucunda tüm maddeleri içeren özgün ölçeğin Cronbach alfa değerinin .92 ile .95 arasında değiştiği rapor edilmiştir. Ölçeğin iki ay ara ile uygulanan test-tekrar test güvenirliği ise .80'dir (Kahn ve Hessling, 2001).

ÖSAÖ'deki ölçek maddeleri 5'li Likert tipi bir derecelendirme üzerinden yanıtlamaktadır. Ölçekte yer alan 2., 4., 5., 8., 9., ve 10. maddeler ters puanlanmaktadır. Özgün ölçekten alınabilecek en düşük puan 12 ve en yüksek puan 60'dır. Ölçek puanlarının yüksek olması, bireylerin öznel sıkıntılarını açma eğiliminde olduklarına işaret etmektedir. Ölçeğe ilişkin iki örnek madde "kendimi üzgün hissettiğimde genellikle arkadaşlarıma açılırım (madde 1)" ve "sorunlarım hakkında kimseyle konuşmamayı tercih ederim (madde 2)" şeklindedir.

\section{İşlem}

ÖSAÖ’nün Türkçe’ye uyarlanması sürecinde öncelikle Mersin Üniversitesi Rektörlüğünden gerekli izinler alınmış, ardından çeviri işlemi ile geçerlik ve güvenirlik çalışmaları gerçekleştirilmiştir. Ölçeğin uyarlama aşamasında çeviri-tekrar (geriye) çeviri yöntemi kullanılmıştır. Bu süreçte, ilk olarak ölçeğin İngilizce formunda yer alan maddeler önce araştırmacılar tarafından, sonrasında da Mersin Üniversitesi, Eğitim Bilimleri Bölümü’nde görevli iki öğretim üyesi ile Yabancı Diller Eğitimi Bilim Dalında görevli bir araştırma görevlisi tarafından detaylı incelenerek Türkçe'ye çevrilmiştir. Birbirinden bağımsız şekilde gerçekleştirilen çeviriler, araştırmacılar tarafından madde düzeyinde tek tek ele alınarak, her bir maddeyi en uygun betimleyen ifadelerin belirlenmesi sağlanmıştır. Ardından, Mersin Üniversitesi Eğitim Fakültesi'nde görevli ve iyi seviyede İngilizce bilen iki öğretim üyesi, 
Türkçe'ye uyarlanan ölçek maddelerini yeniden İngilizce'ye çevirmiştir. Tekrar çevirisi gerçekleştirilen ölçek ile orijinal ölçek araştırmacılar tarafından karşılaştırılmış ve her iki ölçek formundaki maddelerin anlamsal ve dilbilimsel açıdan uyumluluğu denetlenmiştir. Her iki form arasında oluşan tutarlılık boyutunda ölçeğin Türkçe formuna son biçim verilmiştir. Bir sonraki aşamada, ölçeğin Türkçe formu 20 üniversite öğrencisine sunulmuş ve öğrencilerden her bir maddeyi anlaşılabilirlik düzeyinde değerlendirmeleri ve açık olmayan tümceleri belirlemeleri istenmiştir. Öğrencilerin geribildirimleri çerçevesinde son düzenlemeleri yapılan ölçekteki her maddenin anlamsal ve dilbilimsel bütünlük sağladığı kararlaştırılmış ve ölçek kullanıma hazır duruma getirilmiştir. Uygulama sürecinde öğrencilerin bu çalışmaya gönüllü katılımı esas alınmış, bütün katılımcılara araştırmanın amacı ve ölçeğin uygulanma yönergesi standart olarak açıklanmıştır. Uygulamalar yaklaşık olarak 10 dakika sürmüştür.

\section{Verilerin Analizi}

$\mathrm{Bu}$ çalışmada, ölçeğin yapı geçerliğini test etmek üzere doğrulayıcı faktör analizi (DFA) kullanılmıştır. DFA analizleri LISREL 8.30 (Jöreskog ve Sörbom, 1993) programı kullanılarak gerçekleştirilmiştir. Çalışma kapsamında oluşturulan yapısal modelin veri tabanına uygunluğunu (model fit) incelemek için çeşitli model uyum iyiliği indekslerinden yararlanılmıştır. $\mathrm{Bu}$ indeksler arasında en sık tercih edilenlerden biri olan ki kare $\left(x^{2}\right)$ uyum testi, önerilen modelin veri tabanına mutlak uygunluğunu sınamak için kullanılır (Bollen, 1989). Diğer yandan, ki kare uyum testi örneklem büyüklügüüne duyarlı olduğu için örneklem sayıs1 200'ün üstünde olduğunda güvenilir sonuçlar vermeyebilmektedir (Schumacker ve Lomax, 1996). Ki kare uyum testinin s1k kullanılan bir indeks olması nedeniyle, $x^{2} / d f$ oranının 2'den küçük bir değer alması, önerilen modelin doğrulanabilirliğini belirleyen temel bir ölçüt olarak gösterilmektedir (Kline, 1998). Önerilen modelin elde edilen veriye uyumunu test etmek için ayrıca SRMR (Standardized root mean square residual; Bentler, 1995), RMSEA (Root mean squared error of approximation; Steiger, 1990), CFI (Comparative fit index; Bentler, 1990), GFI (Goodness-of-fit index; Jöreskog ve Sörbom, 1989) ve AGFI (Adjusted goodness-of-fit index; Jöreskog ve Sörbom, 1989) gibi araştırmalarda en çok yararlanılan model uyum indeksleri de kullanılmıştır. Öngörülen modelin uygunluğunun onaylanması için SRMR ve RMSEA indekslerinin .05 ve altı, CFI, GFI ve AGFI indekslerinin ise .90 ve üzeri bir uyum değerine sahip olması gerekir (Schumacker ve Lomax, 1996). Bu çalışmada yukarıda sözü edilen tüm model uyum indekslerinden yararlanılmıştır. 


\section{Bulgular}

\section{ÖSAÖ’nün Geçerliğine İlişkin Bulgular}

Bu çalışmada, ÖSAÖ’nün faktör yapısını belirlemek ve yapı geçerliğini test etmek üzere doğrulayıcı faktör analizi kullanılmıştır. Bu süreçte, orijinal ÖSAÖ’nün yapı geçerliği çalışmalarında Kahn ve Hessling (2001) tarafından kullanılan yöntem benimsenerek, ölçeğin kuramsal altyapısına uygun şekilde 12 maddenin (6 olumlu ve 6 olumsuz) yer aldığı iki uçlu ve tek boyutlu olduğu öngörülen model başlangıç noktası olarak ele alınmıştır. Bir başka deyişle, öncelikle 12 maddenin tek bir boyuta yüklendiği model test edilmiştir (Model 1). Daha sonra, ilgili madde gruplarının ölçtüğü iki faktörlü yapı sınanmış ve bu faktörlere ilişkin özellikler yeniden incelenmiştir (Model 2). Ardından, ÖSAÖ’de gözlemlenen iki boyutlu yap1 daha çok iki bileşen olarak ele alınmış ve bu iki bileşenin orijinal ölçekte olduğu gibi tek bir üst boyuta yüklendiği sayıltısı test edilmiştir. Bu amaçla, çalışma verilerine ikinci düzey faktör analizi (second-order factor analysis) uygulanmıştır (Model 3). Son olarak, üç modelden elde edilen model uyum indeksleri karşılaştırılarak bir sonuca ulaşılmıştır.

Tablo 1'de yer alan DFA bulgularına ait uyum indeks değerleri incelendiğinde, test edilen ölçme modellerine ait uyum göstergelerinin her bir modelde gittikçe iyileştiği gözlemlenmektedir. $\mathrm{Bu}$ gelişme, yapılan değişikliklerin, orijinal ölçeğin geliştirme çalışmalarına benzer şekilde, hem kavramsal hem de istatistiksel açıdan uygun olduğunun bir göstergesi olarak kabul edilmektedir.

Tablo 1. Test edilen modellere ilişkin uyum indeksleri ve değerleri

\begin{tabular}{ccccccccc}
\hline Modeller & $\boldsymbol{\chi}^{\mathbf{2}}$ & $\boldsymbol{s} \boldsymbol{d}$ & $\boldsymbol{\chi}^{2} / \boldsymbol{s} \boldsymbol{d}$ & RMSEA & SRMR & GFI & AGFI & CFI \\
\hline Model 1 & 136.10 & 44 & 3.09 & .08 & .05 & .98 & .98 & .97 \\
Model 2 & 125.84 & 53 & 2.37 & .07 & .03 & .99 & .99 & .99 \\
Model 3 & 68.03 & 52 & 1.31 & .03 & .03 & 1 & 1 & 1 \\
\hline
\end{tabular}

Model 1: 12 madde ve tek boyutlu model.

Model 2: 12 madde ve 2 boyutlu model.

Model 3: 12 madde, 2 bileşenli ve tek boyutlu model.

ÖSAÖ maddelerinin DFA sonucunda elde edilen standardize edilmiş Lambda $(\lambda)$ değerleri, $t$ değerleri ve çoklu korelasyon kareleri $\left(\mathrm{R}^{2}\right)$ Tablo 2'de verilmektedir. Elde edilen tüm değerler $p<.05$ düzeyinde anlamlıdır. Lambda değerleri açısından ele alındığında, 
maddelerin faktör yük değerleri .49 ile .85 arasında değişmektedir. Bu değerler, maddelerin faktör yüklerinin yeterli ve çoğunlukla yüksek düzeyde olduğunu göstermektedir. Ayrıca, DFA çerçevesinde test edilen iki bileşenli ve tek faktörlü ÖSAÖ modeli, $\chi^{2}(52)=68.03$, $\chi^{2} / s d=1.31, \mathrm{RMSEA}=.032, \mathrm{SRMR}=.031, \mathrm{GFI}=.996, \mathrm{AGFI}=.995$ ve $\mathrm{CFI}=.998$ uyum değerlerine sahiptir. Uyum indekslerinden sağlanan tüm değerler, 12 maddelik, iki bileşenli ve tek faktörlü 3. modelin yapı geçerliğine dair yeterli kanıt bulunduğunu göstermektedir.

Tablo 2. ÖSAÖ maddelerinin standardize edilmiş Lambda, $t$ ve $R^{2}$ değerleri ile aritmetik ortalama ve standart sapmaları $(N=311)$

\begin{tabular}{lcccccc}
\hline \multicolumn{1}{c}{ Faktörler ve } & $\lambda$ & $\boldsymbol{t}$ & $\mathbf{R}^{2}$ & $\begin{array}{c}\text { Madde } \\
\text { Moplam } \\
\text { Morelasyonu }\end{array}$ & $\bar{X}$ & Ss \\
\hline Kendini Açma & .81 & 21.75 & .66 & - & - & - \\
Madde 1 & .83 & 26.94 & .69 & .726 & 2.89 & 1.22 \\
Madde 3 & .77 & 32.43 & .60 & .674 & 3.04 & 1.29 \\
Madde 6 & .80 & 32.73 & .64 & .688 & 2.88 & 1.23 \\
Madde 7 & .85 & 34.39 & .73 & .733 & 2.96 & 1.23 \\
Madde 11 & .82 & 33.03 & .67 & .702 & 2.94 & 1.27 \\
Madde 12 & .75 & 33.37 & .56 & .638 & 2.64 & 1.31 \\
\hline Kendini Gizleme & .79 & 28.74 & .62 & - & - & - \\
Madde 2 & .77 & 21.02 & .60 & .656 & 3.93 & 1.22 \\
Madde 4 & .81 & 28.80 & .66 & .674 & 3.94 & 1.25 \\
Madde 5 & .82 & 27.53 & .67 & .683 & 3.70 & 1.32 \\
Madde 8 & .59 & 25.28 & .35 & .500 & 3.66 & 1.37 \\
Madde 9 & .49 & 21.68 & .25 & .417 & 3.78 & 1.22 \\
Madde 10 & .74 & 27.21 & .55 & .616 & 4.03 & 1.26 \\
\hline & & & & & & \\
\hline
\end{tabular}

Bununla birlikte, ÖSAÖ’de yer alan faktörlere yüklenen maddeler incelendiğinde, ikinci bileşenin sadece ölçekte ters puanlanan maddelerden oluştuğu gözlemlenmektedir. Ayrıca, DFA sonucunda elde edilen iki bileşen arasındaki korelasyon katsayısı .59'dur. $\mathrm{Bu}$ durum, Kahn ve Hessling (2001) tarafından orijinal ölçek için yapılan geçerlik çalışmalarında 
belirtildiği üzere ÖSAÖ’nün iki uçlu (bipolar) ve iki bileşenli bir yapıya sahip olduğunu göstermektedir. Sonuç olarak, ÖSAÖ’nün ayırt edici özellikleri bulunan 12 madde ile 2 bileşenli ve tek faktörlü bir yapıya sahip olduğu doğrulayıcı faktör analizine göre belirlenmiş ve bu model kuramsal ve istatistiksel açıdan uygun ve tatminkâr bulunmuştur.

\section{ÖSAÖ’nün Güvenirliğine İlişkin Bulgular}

ÖSAÖ’nün güvenirliğini incelemek amacıyla Cronbach alfa iç tutarlık ve test-tekrar test yöntemleri kullanılmıştır. Ölçeğin iç tutarlığını belirlemek için yapılan analiz sonucunda Cronbach alfa değeri "kendini açma" için .92; "kendini gizleme" için .86 bulunmuştur. Ölçeğin geneline ve kapsadığı tüm boyutlara ilişkin Cronbach alfa değeri ise . 91 olarak belirlenmiştir. $\mathrm{Bu}$ bulgular, ölçeğin yüksek düzeyde iç tutarlığa sahip olduğunu göstermektedir.

Bununla birlikte, test-tekrar test güvenirliğinin incelenmesi için ÖSAÖ, 97 üniversite öğrencisine, üç hafta arayla yeniden uygulanmıştır. Analiz sonucunda elde edilen korelasyon değerleri iki ayrı uçta yer alan "kendini açma" için .83 ve "kendini gizleme" için .74 olarak hesaplanmıştır. Ölçeğin geneline ve kapsadığ tüm bileşenlere ilişkin korelasyon değeri ise .85 olarak belirlenmiştir.

\section{Tartışma ve Sonuç}

$\mathrm{Bu}$ çalışmada, üniversite öğrencilerinin öznel sıkıntılarını açma düzeylerinin belirlenebilmesi amacıyla geliştirilen Öznel Sıkıntıları Açma Ölçeği'nin Türkçe formunun geçerlik ve güvenirliği incelenmiştir. Çalışma kapsamında gerçekleştirilen DFA analizleri sonucunda, adı geçen 12 maddelik iki uçlu ölçeğin, her biri altı maddeden oluşan "kendini açma" ve "kendini gizleme" olarak adlandırılan iki bileşenli ve tek faktörlü bir yapı sergilediği belirlenmiştir. Bu sonuçlar, ÖSAÖ’nün yapı geçerliğinin bulunduğunu ortaya koymaktadır. DFA sonuçları çerçevesinde son şekli verilen ölçeğin yapılan güvenirlik analizi sonucunda Cronbach alfa iç tutarlık katsayısı ise .91 olarak belirlenmiştir. Bu bulgu, ÖSAÖ’nün güvenirliğinin yüksek düzeyde olduğunu göstermektedir. Sonuç olarak, ÖSAÖ’nün yapı geçerliğinin incelenmesi sonucunda belirlenen iki uçlu (bipolar) ve tek boyutlu yapının, özgün ölçeğin geliştirilmesi kapsamında yürütülen araştırma bulgularıyla (Kahn ve Hessling, 2001) tam anlamıyla örtüştüğü ve belirlenen yüksek güvenirlik değerlerinin de sözü edilen çalışmada elde edilen değerlerle büyük oranda benzerlikler taşıdığı gözlemlenmektedir. Ortaya çıkan bu sonuç, ÖSAÖ’nün kültürlerarası bir tutarlığa sahip olduğuna yönelik önemli bir gösterge olarak nitelendirilebilir. 
Kahn ve Hessling (2001), kuramsal olarak bireylerin bir zaman dilimi içinde kendini açmaya karşı kendini gizleme eğilimlerinin birlikte ele alınarak incelenmesinin bu iki kavramı birbirinden bağımsız olarak ele almaktan çok daha etkili bir yaklaşım olduğunu belirtmektedirler. Özellikle, kişisel sırlar, yaşamı tehdit eden hastalıklar ya da travmatik yaşam olayları gibi çok çeşitli olgular karşısında bireylerin kendini açma/gizleme eğilimlerinin bütünleyici bir yaklaşım temelinde birlikte ele alınması ile birbirinden ayrıştırılan iki ortak kavrama ait farklı alanyazın oluşumunun da önüne geçilmiş olacaktır (Kahn ve Hessling, 2001). Bir başka deyişle, bireylerin herhangi bir konu üzerinde sadece kendilerini açma eğilimleri olup olmadığını incelemek yerine, zamana ve olaya bağlı olarak kendini açma ya da kendini gizleme eğilimlerinden hangisine yöneldiklerine odaklanmak çok daha kapsayıcı bir bakış açısı kazandıracaktır.

Dolayısıyla, Öznel Sıkıntıları Açma Ölçeği kullanılarak yapılacak çalışmalarla, üniversite öğrencilerinin kendini açma ya da gizleme eğilimlerinin bireysel psikolojik danışma süreci ve psikolojik danışma çıktıları üzerindeki olası etkilerinin belirlenmesine olanak sağlanabileceği düşünülmektedir. Benzer şekilde, ÖSAÖ yardımıyla, üniversite öğrencilerinin öznel sıkıntıları çerçevesinde kendini açma ve kendini gizleme düzeylerinin psikolojik yardım arama, cinsiyet ve cinsiyet rolleri, kaygı, depresyon, benlik saygısı, yaşam doyumu, sosyal destek algısı, kendini damgalama, sosyal damgalama vb. çok çeşitli değişkenlerle ilişkisinin ortak bir yapı içinde incelenebileceği değerlendirilmektedir.

$\mathrm{Bu}$ araştırmanın sonuçları, çalışma grubunu oluşturan ve sadece bir üniversitede öğrenim görmekte olan 311 üniversite öğrencisinden elde edilen verilere dayanmaktadır. $\mathrm{Bu}$ durum, araştırmanın bir sınırlılığı olarak değerlendirilebilir. Geçerlik ve güvenirlik çalışmaları, yapılan ölçümler temelinde gerçekleştirildiğinden, gelecek dönemlerde daha geniş örneklem sayıları ile farklı yaş ve örneklem gruplarından (ergenler, yetişkinler, psikolojik danışma yardımı alanlar vb.) sağlanan verilerle ÖSAÖ’nün psikometrik özelliklerinin yeniden incelenmesinin uygun olacağı düşünülmektedir. Yine, zaman serisi desenli araştırma yaklaşımı temelinde üniversite öğrencilerinin kendini açma düzeylerinde zamana bağlı değişimlerin olup olmadığının araştırılması yararlı olacaktır. Sonuç olarak, ÖSAÖ Türkçe formunun üniversite öğrencilerinin öznel sıkıntılarını (kendilerini) açma düzeylerinin belirlenmesi amacıyla kullanılabilecek yeterli psikometrik özelliklere sahip olduğu söylenebilir. Dolayısıyla, ÖSAÖ, ilgili alandaki araştırmacıların yanı sıra üniversitelerin psikolojik danışma merkezlerinde görev yapan ruh sağlığı uzmanları tarafından 
Ege Eğitim Dergisi 2017 (18) 2: 557-575

Öznel Sıkıntıları Açma Ölçeği: Geçerlik ve Güvenirlik Çalışmaları

bu çalışmadaki katılımcılarla benzer özellikteki bireylerin öznel sıkıntılarını açma düzeylerini belirlemek amacıyla kullanılabilir. 


\section{Kaynakça}

Bahar, M. (2010). Kredi ve yurtlar kurumu yurtlarında barınan öğrencilerin stres kaynakları, madde kullanım düzeyleri ve psikolojik yardım arama davranışları. (Yayınlanmamış yüksek lisans tezi). Karadeniz Teknik Üniversitesi, Trabzon.

Bentler, P.M. (1990). Comparative fit indices in structural models. Psychological Bulletin, $107,238-246$.

Bentler, P. M. (1995). EQS structural equations program manual. Encino, CA: Multivariate Software.

Bollen, K. A. (1989). Structural equations with latent variables. New York: John Wiley \& Sons.

Cepeda-Benito, A. ve Short, P. (1998). Self-concealment, avoidance of psychological services and perceived likelihood of seeking professional help. Journal of Counseling Psychology, 45(1), 858-864.

Chang, H. (2007). Psychological distress and help-seeking among Taiwanese college students: Role of gender and student status. British Journal of Guidance \& Counselling, 35(3), 347-355.

Cozby, P. C. (1973). Self-Disclosure: A literature review. Psychological Bulletin, 79, 73-91.

Cramer, K. M. (1999). Psychological antecendents to help seeking behavior a reanalysis using path modeling structures. Journal of Counseling Psychology, 46(3), 381-387.

Çebi, E. (2009). University students' attitudes toward seeking psychological help: effects of perceived social support, psychological distress, prior help-seeking experience and gender. (Unpublished master's thesis). Middle East Technical University, Ankara.

Gizir, C. A. (2005). Orta Doğu Teknik Üniversitesi son sınıf öğrencilerinin problemleri üzerine bir çalışma. Mersin Üniversitesi Eğitim Fakültesi Dergisi, 1, 196-213.

Greenidge, W. L. (2007). Attitudes towards seeking professional counseling: The role of outcome expectations and emotional openness in english-speaking Caribbean college students in the U.S. and the Caribbean. (Unpublished doctoral thesis). University of Central Florida, Florida.

Greenidge. W. L. ve Daire, A. P. (2010). The relationship between emotional opennes and the attitudes towards seeking professional counseling of English-Speaking Caribbean 
college students. International Journal for The Advancement of Counseling, 32, 191201.

Greenland, K., Scourfield, J., Maxwell, N., Prior, L. ve Scourfield J. (2009). Theoretical antecedents of distress disclosure in a community sample of young people. Journal of Applied Social Psychology, 39, 2045-2068.

Jourard, S. M. (1979). Influence of an interviewer's disclosure on the self-disclosing behavior of interviewees. Journal of Counseling Psychology, 18(6), 595-600.

Jöreskog, K. ve Sörbom, D. (1989). LISREL 7 user's reference guide. Chicago: Scientific Software.

Jöreskog, K. G. ve Sörbom, D. (1993). LISREL 8: A guide to the program and applications. Chicago: Scientific Software International.

Kahn, J. H. ve Hessling, R. M. (2001). Measuring the tendency to conceal versus disclose psychological distress. Journal of Social and Clinical Psychology, 20(1), 41-65.

Kakhnovets, R. (2011). Relationships among personality, expectations about counseling, and help-seeking attitudes, Journal of Counseling \& Development, 89, 11-19.

Kalkan, M. ve Odacı, H. (2005). Cinsiyet ve cinsiyet rolünün psikolojik yardım almaya ilişkin tutumlarla ilişkisi. Türk Psikolojik Danışma ve Rehberlik Dergisi, 3(23), 57-64.

Karataş, A. ve Gizir, C. A. (2013). Üniversite öğrencilerinin psikolojik danışma gereksinimlerinin çeşitli değişkenler açısından incelenmesi. Hacettepe Üniversitesi Ĕ̈itim Fakültesi Dergisi, 28(3), 250-265.

Kelly, A. E. ve Achter, S. A. (1995). Self-concealment and attitudes toward counseling in university students. Journal of Counseling Psychology, 42(1), 40-46.

Kim, B.S.K. (2007). Adherence to asian and european american cultural values and attitudes toward seeking professional psychological help among asian american college students. Journal of Counseling Psychology, 54, 474-480.

Kline, R. B. (1998). Principles and practices of structural equation modeling. New York: The Guilford Press.

Komiya, N. ve Eels, G. T. (2001). Predictors of attitudestoward seeking counseling among international students. Journal of College Counseling, 4, 153-160. 
Komiya, N., Good, G. E. ve Sherrod, N. B. (2000). Emotional openness as a predictor of college students' attitudes toward seeking psychological help. Journal of Counseling Psychology, 47, 138-143.

Koydemir, S., Erel, O., Yumurtac1, D., ve Şahin, G. N. (2010). Psychological helpseeking attitudes and barriers to help-seeking in young people in turkey. International Journal of Advancement 32, 274-289.

Koydemir-Özden, S. ve Erel, Ö. (2010). Psychological help-seeking: Role of sociodemographic variables, previous help-seeking experience and presence of a problem. Procedia Social and Behavioral Sciences, 5, 688-693.

Larson, D. G. ve Chastain, R. L. (1990). Self-concealment: Conceptualization, measurement, and health implications. Journal of Social and Clinical Psychology, 9, 439-455.

Özbay, Y., Terzi, Ş., Erkan, S. ve Cihangir-Çankaya, Z. (2011). Üniversite öğrencilerinin profesyonel yardım arama tutumları, cinsiyet rolleri ve kendini saklama düzeyleri. Pegem Ĕ̈itim ve Ögretim Dergisi, 1(4), 59-71.

Raunic, A. ve Xenos, S. (2008). University counseling service utilization by local and international students and user characteristics: A review. International Journal of Advanced Counselling, 30, 262-267.

Rosenthal, B. ve Wilson, C. (2008). Mental health services: Use and disparity among diverse college students. Journal of American College Health, 57, 61-67.

Schumacher, R. E. ve Lomax, R. G. (1996). A beginner's guide to structural equation modeling. New Jersey: Erlbaum.

Stallman, H. M. ve Shochet, I. (2009). Prevalence of mental health problems in Australian university health services. Australian Psychologist, 44, 122-127.

Steiger, J. H.(1990). Some additional thoughts on components, factors, and factor indeterminancy. Multivariate Behavioral Research, 25(1), 41-45.

Sevinç, S. ve Gizir, C. A. (2014). Üniversite birinci sınıf öğrencilerinin üniversiteye uyumlarını olumsuz etkileyen faktörlere yönelik algılarının incelenmesi (Mersin Üniversitesi örneği). Kuram ve Uygulamada Eğitim Bilimleri Dergisi, 14(4), 1285 1308 . 
Topkaya, N. (2014). Psikolojik yardım almaya ilişkin tutumu yordamada cinsiyet, psikolojik yardım alma nedeniyle kendini damgalama ve sosyal damgalanma. Kuram ve Uygulamada Ĕ̈itim Bilimleri, 14(2), 1-17.

Turner, A. L. ve Quinn, K.F. (1999). College students' perceptions of the value of psychological services: A comparison with APA's public education research. Professional Psychology: Research and Practice, 30, 368-371.

Türküm, A. S. (2005). Who seeks help? examining the differences in attitude of Turkish university students toward seeking psychological help by gender, gender roles and help-seeking experiences. The Journal of Men's Studies, 13, 389-401.

Vogel, D. L. ve Wester, S. R. (2003). To seek help or not to seek help: The risks of selfdisclosure. Journal of Counseling Psychology, 50, 351-361.

Vogel, D. L., Wester S. R. ve Larson, M. L. (2007). Avoidance of counseling: Psychological factors that inhibit seeking help. Journal of Counseling \& Development, 85, 410-422.

Vogel, D. L., Wester, S. R., Wei, M. ve Boysen, G. A. (2005). The role of outcome expectations and attitudes on decisions to seek professional help. Journal of Counseling Psychology, 52, 459-470. 


\section{Extended Abstract}

A review of the literature reveals several variables that are believed to negatively impact one's attitude towards seeking professional counseling. Some of these include a fear of disclosing distressing information, social stigma attached to mental health services, avoidance of painful emotions, low level of self-disclosure, anticipated risks, self-concealment, traditional male gender roles, low socioeconomic status, low educational level, and ethnic minority status (Kahn \& Hessling 2001; Kelly \& Achter 1995; Komiya et al. 2000; Vogel \& Wester 2003). The implications of whether a person decides to talk about his or her problems have been the focus of two bodies of literature; describing self-concealment and selfdisclosure. While research in these two areas has made important contributions to the understanding of the physical and mental health implications of revealing problems, these literatures have been developed somewhat independently of each other, thereby limiting the integration of theory (Kahn \& Hessling, 2001). Distress disclosure can be operationally defined as the degree to which a person is comfortable talking to others about personally distressing information (Kahn \& Hessling 2001). A high level of distress disclosure indicates a strong ability to and level of comfort with disclosing personal information with others, and more particularly with strangers. A low level of distress disclosure has been linked to negative attitudes towards professional counseling and consequent avoidance of mental health services. A low level of distress disclosure is also associated with triggering treatment fear in individuals who need professional counseling services (Komiya et al., 2000). One of the most widely used instruments in order to identify the self-disclosure is the Distress Disclosure Index (DDI; Kahn \& Hessling, 2001). The Distress Disclosure Index was developed as a generic measure of the tendency to disclose negative events or psychological distress. High scores on the DDI have been associated with increased self-esteem, life satisfaction, and social support and with decreased psychological distress, loneliness, and depression 
(Greenland et. al. 2009). The DDI is useful in understanding psychological well-being, interpersonal relationships, and help-seeking behavior (Kahn \& Hessling, 2001; Kahn \& Williams, 2003; Vogel \& Wester, 2003; Vogel, Wester, Wei, \& Boysen, 2005). It is also a useful tool for academics, clinicians, and social-care staff. Consequently, the purpose of the present study was to adapt the DDI (Kahn \& Hessling, 2001) to Turkish-language and investigate the validity and reliability of the scale.

The sample of the study consisted of 311 (195 female, 116 male) undergraduates enrolled in 4 faculties (Arts \& Sciences, Education, Engineering, and Economics \& Administrative Sciences) at Mersin University. The DDI which was originally developed by Kahn and Hessling (2001) consists of 12 items to which individuals respond on a 5-point Likert type scale. Total scores on the DDI can change from 12 to 60 , with higher scores indicating greater tendency to personal distress disclosure. The original scale is bipolar and composed of 2 factors namely, "self-disclosure" and "self-concealment". The total 12-item DDI scale has an alpha level of .92-.95, respectively. In the present study, confirmatory factor analysis was used to obtain the construct validity evidence of the Turkish version of DDI. Confirmatory factor analysis (CFA) was used to evaluate the construct validity of the scale by using LISREL 8.30 for Windows with SIMPLIS Command Language (Jöreskog \& Sörbom, 1993). For all the statistical procedures performed, the alpha value of .05 was established as a level of significance and the maximum likelihood (ML) estimation method was used.

The result of the CFA for the preferred model of DDI yielded following goodness-offit indices: $\mathrm{x}^{2}(52)=68.03, \mathrm{x}^{2} / s d=1.31, \mathrm{RMSEA}=.032, \mathrm{SRMR}=.031, \mathrm{GFI}=.996, \mathrm{AGFI}=$ .995 , and CFI $=.998$. These indices were deemed adequate to treat the respective observed variable groups as distinct latent variables in the structural model. All parameter estimates were statistically significant $(p<.05)$. Moreover, all Lambda-x values, which are the loadings of each observed variable on respective latent variable, ranged from .49 to .85 . Thus, the 
results of the study indicated that the scale has a unidimensional construct based on a bipolar spectrum of "self-disclosure" and "self-concealment". The internal consistencies as estimated by Chronbach alpha for the two latent variables of DDI is .91. This result indicated that the reliability evidence for DDI was highly satisfactory. The original bipolar structure of the DDI was basically adapted to Turkish and basically replicated with Turkish university students in the current study. Moreover, the result of the confirmatory factor analysis indicated that the factor structure of the original DDI was also similar for Turkish respondents. To conclude, this study provided preliminary support for the psychometric properties of the Turkish version of the DDI for university students. 